\title{
Functional outcome among patients treated by percutaneous cannulated screw with tension band for transverse patella fracture
}

\author{
Rabi Mohan Dhakal ${ }^{* 1}$, Rabindra Prasad Shrestha1, Bhola Shresha', \\ Ishwor Sharma Kandel', Karuna Acharya², Krishna Bhadhur Bista', Pravakar Parajuli \\ 'Department of Orthopedics Surgery, ²Department of Emergency Medicine, \\ Gandaki Medical College Teaching Hospital and Research Center
}

\begin{abstract}
Introduction: Tension band wiring is the most commonly used treatment method for transverse patella fracture. Tension band construct can be achieved by various modifications. Percutaneous cannulated screw with tension band is a minimally invasive technique with stiffer fixation that follows tension band principle. This study aims to assess the clinical and radiological outcome using percutaneous cannulated screw with tension band for the management of transverse patella fracture. Methods: This was a prospective study among 30 adult patients who had closed displaced transverse patella fracture. Patients with polytrauma, comminuted fracture, neurovascular injury and prior injury to the limb were excluded from the study. Each patient was followed up at two weeks, four weeks, three months and six months postoperatively. Results: Among all surgically treated patients using this technique, pain gradually decreased over time and the pain score was less than one in all patients at six months follow-up with an average score of 0.3 . The final range of motion at six months was: flexion ranging from 122 to 145 degrees and extension lag from 0 to 8 degrees. There was significant improvement in range of motion of knee in each follow up. The mean duration for fracture union was $11.4 \pm 2.3$ weeks. There were no cases of nonunion and hardware failure. The mean Lyshom score was 82.5 at final follow up. Conclusions: The percutaneous fixation of transverse patella fracture with cannulated screw and stainless steel wire is safe and effective method which gives good functional outcome.
\end{abstract}

Keywords: Cannulated screw, patella fracture, percutaneous.

\section{*Correspondence:}

Dr. Rabi Mohan Dhakal

Associate Professor, Department of Orthopedics

Gandaki Medical College Teaching Hospital, Pokhara, Nepal

Email: dhakalrabi@hotmail.com

Submitted: August 2, 2021

Accepted: August 19, 2021

To cite: Dhakal RM, Shrestha RP, Shrestha B, Kandel IS, Acharya K, Bista KR, et al. Functional outcome among patients treated by percutaneous cannulated screw with tension band for transverse patella fracture. JGMC Nepal. 2021;14(2):122-6.

DOI: $10.3126 /$ jgmcn.v14i2.38937

\section{INTRODUCTION}

Patella is the largest sesamoid bone in human body and mainly functions to increase the efficacy of extensor mechanism of knee. Patella fracture accounts for around $1 \%$ of injuries. ${ }^{1}$ Patella fracture can be due to direct or indirect force. Indirect force due to excessive stretching or contraction of extensor mechanism leads to transverse patella fracture while a direct blow generally causes comminuted fracture. If the fracture is displaced and extensor mechanism is disrupted, operative treatment is indicated. ${ }^{2}$ The objectives of the operative treatment is anatomical reduction with congruent joint and restoration of extensor mechanism with firm fixation. ${ }^{3}$

Tension band wiring wires are most commonly used treatment method for transverse patella fracture. It works by transforming the tensile forces into compression at the articular patellar surface during knee flexion. ${ }^{4}$ Tension band construct can be achieved by various modifications. Generally, it is done by open technique. Modified anterior tension band with $\mathrm{K}$ wires after open reduction are most widely used methods but are subjected to hardware irritation. ${ }^{5}$ 
Use of suture materials instead of 18-gauge stainless steel (SS) wires have shown similar strength with less hardware irritation. ${ }^{6}$ But these techniques are generally done with open reduction which requires extensive soft tissue dissection. It also has more intra-operative blood loss, chance of infection and long scar. These factors have led to use of less invasive methods like percutaneous cannulated screw fixation..$^{7-9}$ Combining percutaneous screw fixation with figure of eight wiring has shown good results. ${ }^{10}$ This is a minimally invasive technique with stiffer fixation and follows tension band principle. This kind of fixation for transverse patella fracture is not carried out frequently.

This study aims to assess the functional outcome using percutaneous cannulated screw with tension band for the management of transverse patella fracture.

\section{METHODS}

This was a prospective study carried out from January 2019 to December 2019 at Gandaki Medical College Teaching Hospital, Pokhara. A total of 30 skeletally mature patients with closed displaced transverse patella fracture were included. Patients with polytrauma, comminuted fracture, neurovascular injury and prior injury to the limbs were excluded from the study. Ethical approval for the study was obtained from the Institutional Ethical Committee of Gandaki Medical College. The patients were enrolled in the study after written consent. Every patient underwent surgery with the same technique and implants as described in operative technique. Each patient was followed up at two weeks, four weeks, three months, and six months postoperatively. All records and data were kept in the proforma.

\section{Operative technique}

After spinal anesthesia, the patient was kept supine and tourniquet was applied. Hematoma was aspirated if the swelling was tense. Fixation construct and technique was similar to Chiang et al. ${ }^{11}$ and Cho et al. ${ }^{12}$ However, we used fluoroscopic guided reduction rather than arthroscopy and a single SS wire. Closed reduction was attempted in full extension of knee with the help of pointed reduction forceps. The reduction was confirmed in anteroposterior and lateral $\mathrm{C}$-arm images. It was accepted if the articular congruency was achieved with no fracture gap. If closed reduction was not achieved, open reduction was done, and those cases were not included in our study. After achieving closed reduction and temporarily holding with pointed reduction clamps, two stab incisions of around $1 \mathrm{~cm}$ were given over the superior pole of patella. Two guide wires were drilled parallel to each other dividing patella into three equal halves and perpendicular to the fracture line. Then $4.0 \mathrm{~mm}$ cannulated screws were kept starting from inferior to superior direction. The length of screw was just short of inferior pole of patella, and it was made sure that screw was not protruding out. Then stab incisions were made accordingly at the lower end of each screw guide wire. Then $4.0 \mathrm{~mm}$ cannulated screws were kept starting from inferior to superior direction after drilling with cannulated drill bit. The length of the screw was just short of superior pole of patella and was made sure the screw was not protruding out. Both guide wires were then removed. Now the $18 \mathrm{G}$ SS wire was inserted through proximal end of lateral screw towards distal end. With the help of stab incisions and a metallic suction tip, the wire was then passed subcutaneously towards proximal end of medial screw. From there the wire was passed towards its distal end and back to proximal end of lateral screw subcutaneously. Now the two ends of wire were brought at lateral side and twisted as in conventional tension band wiring. The final reduction was checked in antero-posterior $\mathrm{AP}$ and lateral $\mathrm{C}$-arm imaged along with dynamic flexion and extension of knee intra-operatively. Postoperatively patients were kept in hinged knee brace for two weeks with isometric muscle strengthening exercises and passive range of motion from day one. Weight bearing with crutches was allowed as tolerated. Active range of motion (ROM) was started after three weeks postoperatively. Full weight bearing was started by eight weeks.

\section{Outcome assessment tools and technique}

Each patient was followed at two weeks, four weeks, three months, and six months postoperatively. At second week, suture was removed, and active range of motion was started. Braces were discarded at 4 weeks. In each follow up, we measured the outcome in terms of Visual Analogue Scale (VAS) score, radiological union, ROM of knee and Lyshom score.

\section{Statistical Analysis}

Data analysis was done using Statistical Package for Social Sciences (SPSS) Version 25.0. Student's t-test was used to compare normally distributed data while for non-normal distribution, Mann-Whitney $U$ test was used. Pairedsamples t-test was used to compare means of VAS and ROM. Categorical variables were assessed with the use of chi-squared tests. The $P$ value was set at a significance level of 0.05 . 


\section{RESULTS}

In the one-year duration, 35 patients with transverse displaced patella fracture in adult age group were admitted in our hospital. Among them, three cases needed open reduction and were not included while two cases were lost to follow-up during the study. So data of 30 patients were analyzed in this study. 25 patients had middle third transverse patella fracture while five patients had distal third transverse patella fracture and all cases were noncomminuted.

The mean age of participants was $42 \pm 9.7$ years with the range being 27 to 68 years. The proportion of injury was more in males $(n=22,73.33 \%)$. Both sides were similarly injured. The mode of injury was road traffic accident $(n=15$, $50 \%)$, fall from height $(n=13,43.33 \%)$ and fall during sport activities $(n=2,6.67 \%)$ (Table 1$)$. There were no neurovascular injuries preoperatively and intraoperatively. Mean surgical time was $73 \pm 9.3$ minutes.

Table 1: Demographic variables $(\mathrm{N}=30)$

\begin{tabular}{lcc}
\hline Demographic variables & Number & Percent \\
Gender & 22 & 73.3 \\
Male & 8 & 26.7 \\
Female & & \\
Side & 17 & 56.7 \\
Left & 13 & 43.3 \\
Right & & \\
Mechanism & 15 & 50.0 \\
Road traffic accident & 13 & 43.3 \\
Fall injury & 2 & 6.7 \\
Sports-related trauma & & \\
\hline
\end{tabular}

Outcomes were measured using VAS score and ROM of knee in each follow-up, duration for radiological union and outcome score of Lyshom.

Pain gradually decreased over time and was less than VAS score of one in all patients at six months follow-up with an average score of 0.3 . The pain score difference at three months was statistically lower $(\mathrm{p}=0.05)$ than that at four weeks, and at six month was statistically lower than that at three months. The mean range of motion was 11 to 79 degrees at two weeks. The final range of motion at six months was: flexion ranging from 122 to 145 degrees and extension lag from 0 to 8 degrees. There was significant improvement in range of motion of knee in each follow up. The mean duration for fracture union was $11.4 \pm 2.3$ weeks. There were no cases of nonunion and hardware failure. The mean Lyshom score was 82.5 at final follow up.
Overall, complications were seen in $20 \%$ of patients. There were two cases of superficial skin infection which were treated with oral antibiotics and dressing while one patient had loss of fracture reduction on the $4^{\text {th }}$ week of follow-up. The fracture was at the distal third and there was disengagement of hardware from distal pole during knee flexion. Painful hardware or hardware irritation was present in $10 \%$ of the patients. There were no other complications during the six months period.

Table 2: Outcome variables

\begin{tabular}{|c|c|c|}
\hline Outcome Parameters & Mean \pm SD & $P$ value \\
\hline \multicolumn{3}{|l|}{ Pain (VAS) } \\
\hline 2 weeks & $6.4 \pm 3.1$ & 0.09 ( 4 weeks - 2 weeks) \\
\hline 4 weeks & $3.2 \pm 2.9$ & $<0.001$ ( 4 weeks -3 months) \\
\hline 3 months & $1.9 \pm 1.8$ & $<0.001$ (6months -3 months) \\
\hline 6 months & $0.3 \pm 0.7$ & \\
\hline \multicolumn{3}{|l|}{ Flexion $\left({ }^{\circ}\right)$} \\
\hline 2 weeks & $79.3 \pm 12.5$ & $<0.001$ ( 4 weeks - 2 weeks) \\
\hline 4 weeks & $98.7 \pm 15.2$ & $<0.001$ ( 4 weeks - 3 months) \\
\hline 3 months & $132.0 \pm 9.8$ & $<0.001$ (6months -3 months) \\
\hline 6 months & $141.5 \pm 9.9$ & \\
\hline \multicolumn{3}{|l|}{ Extension lag $\left({ }^{\circ}\right)$} \\
\hline 2 weeks & $11.4 \pm 4.3$ & $<0.001$ ( 4 weeks - 2 weeks) \\
\hline 4 weeks & $9.8 \pm 3.2$ & $<0.001$ ( 4 weeks -3 months) \\
\hline 3 months & $5.4 \pm 1.1$ & $<0.001$ (6months -3 months) \\
\hline 6 months & $2.6 \pm 1.9$ & \\
\hline Radiological union (weeks) & $11.4 \pm 2.3$ & \\
\hline Lyshom score & $82.5 \pm 8.4$ & \\
\hline Complications & Frequency (\%) & \\
\hline Hardware Irritation & $3(10)$ & \\
\hline Superficial skin infection & $2(6.7)$ & \\
\hline Loss of reduction & $1(3.3)$ & \\
\hline
\end{tabular}

\section{DISCUSSION}

Open reduction and internal fixation with modified tension band wiring for displaced transverse patellar fracture is a well-established and commonly used treatment option. ${ }^{13}$ But infection, delayed wound healing, broken wires, irritation, immigration of Kirschner (K) wires, fixation failure, and revision are well reported complications of the technique. ${ }^{14-16}$ So less invasive percutaneous techniques are being used which have shown promising results., ${ }^{9,12,17}$ Percutaneous osteosynthesis using $\mathrm{K}$ wires and SS wire was performed by Pizarro et al. ${ }^{9}$ while other percutaneous technique uses cannulated cancellous (CC) screw instead of $\mathrm{K}$ wires. Percutaneous $\mathrm{CC}$ screw with anterior tension band wiring principle is a new technique which has been described by few authors with fluoroscopic or arthroscopic assistance. $^{10,12}$ Biomechanical study in cadavers by 
Carpenter et al. ${ }^{18}$ has used tension band wiring with cancellous screw rather than traditional tension band wiring. ${ }^{19}$ In this study, we aimed to look for the functional and radiological outcome using less invasive technique using percutaneous CC screw with tension band applied percutaneously. Reduction could be assessed using arthroscopy or fluoroscopic guidance. In our study we did fluoroscopy guided closed reduction as it was technically less demanding. However arthroscopic evaluation gives benefit of less radiation exposure and better visualization of articular surface reduction. ${ }^{11}$

Ching et al. ${ }^{10}$ compared minimally invasive technique with open technique where he found surgical time to be significantly longer in the open group compared to percutaneous group $(70.4 \pm 12.5$ vs $79.8 \pm 15.7)$. Similarly, their study showed significantly better functional outcome in percutaneous group (Lhysom score $93.6 \pm 3.1$ vs $88.8 \pm$ 6.7). In a study by Lin et al. ${ }^{20}$ comparing modified anterior TBW with percutaneous cannulated screw fixation, the mean score was $86.7 \pm 6.4$ in the screw group vs $81.5 \pm$ 4.6 in open group. Khan et al. $^{21}$ used fixation construct similar to our study but open reduction of fracture was done. In their study, average duration for union was 10.7 weeks with only two complications among 25 patients. At three months the knee flexion was 113.8 degrees. We had similar union duration and complications but flexion at three months was higher in our study which could be due to decreased soft tissue insult during surgery in percutaneous fixation. Ching et al. ${ }^{11}$ found extension to be $-0.7 \pm 3.9$ ( -8 to 5 ) degrees while flexion to be $140.8 \pm 5.2$ (135-150) degrees. In that study arthroscopic assisted closed reduction technique was used and the findings were similar to our study. The final range of motion at 6 months was flexion ranging from 122 to 145 degrees and extension lag from 0 to 8 degrees which was similar to other studies that used percutaneous fixation., 12

VAS score of $0.3 \pm 0.7$ at 6 months was observed in our study. Luna-Pizzaro et al. ${ }^{9}$ found mean VAS score of $6.2 \pm$ 1.4 in open group which was significantly higher compared to the score of percutaneous group $(3.7 \pm 1.6)$. We also had similar VAS score of $3.2 \pm 2.9$ in fourth week.

As the patella is subcutaneous bone, hardware and soft tissue complications are expected. ${ }^{22}$ We had $20 \%$ complications in our study. Luna-Pizzaro et al. ${ }^{9}$ reported $11 \%$ complication rate including superficial skin infection, displaced fragment and painful hardware which is significantly lower than the open group (40\%). Other studies have also shown higher complications in open group compared to percutaneous fixation. ${ }^{10,14}$

This study had relatively smaller sample size with no long term follow up. There was no randomization and could have led to selection bias and also the surgeons performing the surgeries were different.

\section{CONCLUSIONS}

Percutaneous fixation of transverse patella fracture with cannulated screw and SS wire is safe and effective method which gives good functional outcome. Though technically demanding, it can be easily performed with fluoroscopic guidance.

\section{CONFLICTS OF INTEREST: None declared}

\section{SOURCE OF FUNDING: None}

\section{REFERENCES}

1. Scilaris TA, Grantham JL, Prayson MJ, Marshall MP, Hamilton JJ, Williams JL. Biomechanical comparison of fixation methodsin transverse patellafractures.JOrthop Trauma. 1998;12(5):356-9. DOI: 10.1097/00005131199806000-00011 PMID: 9671189.

2. Schuett DJ, Hake ME, Mauffrey C, Hammerberg EM, Stahel PF, Hak DJ. Current Treatment Strategies for Patella Fractures. Orthopedics. 2015;38(6):37784. DOI: 10.3928/01477447-20150603-05 PMID: 26091213.

3. Della Rocca GJ. Displaced Patella Fractures. J Knee Surg. 2013;26(5):293-300. DOI: 10.1055/s-0033-1353988 PMID: 23966286.

4. Zderic I, Stoffel K, Sommer C, Höntzsch D, Gueorguiev B. Biomechanical evaluation of the tension band wiring principle. A comparison between two different techniques for transverse patella fracture fixation. Injury. 2017;48(8):1749-57. DOI: 10.1016/j. injury.2017.05.037 PMID: 28622833.

5. Egol K, Howard D, Monroy A, Crespo A, Tejwani N, Davidovitch R. Patella fracture fixation with suture and wire: you reap what you sew. Iowa Orthop J. 2014;34:63-7. PMID: 25328461.

6. Wright PB, Kosmopoulos V, Coté RE, Tayag TJ, Nana AD. FiberWire is superior in strength to stainless steel wire for tension band fixation of transverse patellar fractures. Injury. 2009;40(11):1200-3. DOI: 10.1016/j. injury.2009.04.011 PMID: 19524229.

7. Ali M, Alzahrani AW. Percutaneous crossing screws, 
a novel technique for transverse patella fractures. Journal of Orthopaedics Trauma Surgery and Related Research. 2017;12(3).

8. Mao N, Liu D, Ni H, Tang H, Zhang Q. Comparison of the cable pin system with conventional open surgery for transverse patella fractures. Clin Orthop Relat Res. 2013;471(7):2361-6. DOI: 10.1007/s11999-0132932-8 PMID: 23529632.

9. Luna-Pizarro D, Amato D, Arellano F, Hernández A, López-Rojas P. Comparison of a technique using a new percutaneous osteosynthesis device with conventional open surgery for displaced patella fractures in a randomized controlled trial. J Orthop Trauma. 2006;20(8):529-35. DOI: 10.1097/01. bot.0000244994.67998.1b PMID: 16990723.

10. Chiang C, Chen WM, Lin CF, Chen CF, Huang CK, Tzeng $\mathrm{YH}$,et al. Comparison of a minimally invasive technique with open tension band wiring for displaced transverse patellar fractures. Journal of the Chinese Medical Association: JCMA. 2011;74:316-21. DOI: 10.1016/j.jcma.2011.05.008 PMID: 21783097.

11. Chiang CC, Huang CK, Chen WM, Lin CF, Tzeng YH, Liu CL. Arthroscopically assisted percutaneous osteosynthesis of displaced transverse patellar fractures with figure-eight wiring through paired cannulated screws. Arch Orthop Trauma Surg. 2011;131(7):949-54. DOI: 10.1007/s00402-0101241-x PMID: 21188394.

12. Cho JH. Percutaneous cannulated screws with tension band wiring technique in patella fractures. Knee Surg Relat Res. 2013;25(4):215-9. DOI: 10.5792/ ksrr.2013.25.4.215 PMID: 24369000.

13. Benjamin J, Bried J, Dohm M, McMurtry $M$. Biomechanical evaluation of various forms of fixation of transverse patellar fractures. J Orthop Trauma. 1987;1(3):219-22. DOI: 10.1097/00005131198701030-00004 PMID: 3506054.

14. Hoshino CM, Tran W, Tiberi JV, Black MH, Li BH, Gold SM, et al. Complications following tension-band fixation of patellar fractures with cannulated screws compared with Kirschner wires. J Bone Joint Surg Am. 2013;95(7):653-9. DOI: 10.2106/JBJS.K.01549 PMID: 23553301.

15. Agarwala S, Agrawal P, Sobti A. A novel technique of patella fracture fixation facilitating early mobilization and reducing re-operation rates. J Clin Orthop Trauma. 2015;6(3):207-11. DOI: 10.1016/j.jcot.2015.03.009 PMID: 26155061.

16. LeBrun CT, Langford JR, Sagi HC. Functional outcomes after operatively treated patella fractures. J Orthop Trauma. 2012;26(7):422-6. DOI: 10.1097/ BOT.0b013e318228c1a1 PMID: 22183197.

17. Salah AHM, Abd ANM, Mohammad AAT. Percutaneous patellar osteosynthesis. Al-Azhar Medical Journal. 2017;46(1):57-70. DOI: 10.12816/0035535.

18. Carpenter JE, Kasman RA, Patel N, Lee ML, Goldstein SA. Biomechanical evaluation of current patella fracture fixation techniques. J Orthop Trauma. 1997;11(5):3516. DOI: 10.1097/00005131-199707000-00009 PMID: 9294799.

19. Tian Y, Zhou F, Ji H, Zhang Z, Guo Y. Cannulated screw and cable are superior to modified tension band in the treatment of transverse patella fractures. Clin Orthop Relat Res. 2011;469(12):3429-35. DOI: 10.1007/ s11999-011-1913-z PMID: 21573937.

20. Lin T, Liu J, Xiao B, Fu D, Yang S. Comparison of the outcomes of cannulated screws vs. modified tension band wiring fixation techniques in the management of mildly displaced patellar fractures. BMC Musculoskeletal Disorders. 2015;16(1):282. DOI: 10.1186/s12891-015-0719-7 PMID: 26445425.

21. Khan I, Dar MY, Rashid S, Butt MF. Internal Fixation of Transverse Patella Fractures Using Cannulated Cancellous Screws with Anterior Tension Band Wiring. Malays Orthop J. 2016;10(2):21-6. DOI: 10.5704/ MOJ.1607.005 PMID: 28435557.

22. Hung LK, Chan KM, Chow YN, Leung PC. Fractured patella: operative treatment using the tension band principle. Injury. 1985;16(5):343-7. DOI: 10.1016/0020-1383(85)90144-5. 